\title{
Deslizes morais na cena midiática: reprodução da intolerância ou oportunidade para novas gramáticas morais?
}

\section{Regiane Lucas Garcêz e Danila Gentil Rodriguez Cal}

\section{Resumo}

Discute-se de que forma deslizes morais

veiculados nos media reforçam preconceitos ou desvelam questões pouco tematizadas na esfera pública. Qual o papel desses deslizes morais na ampliação das relações de reconhecimento e na transformação das gramáticas morais que regem a sociedade? A partir de uma aproximação entre as teorias do reconhecimento e da deliberação, analisamos a repercussão, na internet, de dois artigos: um sobre o movimento gay, de J. R. Guzzo, publicado na revista Veja, e outro sobre os Guarani Kaiowá, publicado por Walter Navarro na versão on-line do jornal $O$ Tempo. A análise levou em conta: a) o descortinamento de consensos tácitos; b) a possibilidade de discussão acerca de valores com vistas à ampliação de gramáticas morais.

\section{Palavras-chave}

Deslizes Morais. Reconhecimento. Debate Público.

\section{Regiane Lucas Garcêz}

regianelucasgarcez@gmail.com Doutoranda em Comunicação Social pela Universidade Federal de Minas Gerais (UFMG).

\section{Danila Gentil Rodriguez Cal}

danilagentilcal@gmail.com

Doutoranda em Comunicação Social pela Universidade Federal de Minas Gerais (UFMG). Professora da Universidade da Amazônia (Unama).

\section{Introdução}

Pode a ofensa pública contribuir com lutas por reconhecimento? Posicionamentos intolerantes ganham a arena pública por meio dos media exatamente porque fazem parte da vida social de forma latente, porém eles apenas alcançam a categoria de deslize moral e promovem transformações morais quando submetidos ao escrutínio público. Esse é o argumento central deste artigo.

Vez por outra essas expressões de intolerância rotineiras ganham destaque mobilizando as conversações cotidianas e o debate público, seja em sua defesa ou em tom de indignação. Os media certamente possuem papel privilegiado na tematização e identificação de questões de injustiça, seja pelo alcance, seja pelo potencial de pluralidade de vozes que os constituem, 0 que pode favorecer também manifestações de ódio e intolerância.

Neste trabalho, a questão central é discutir quando e como tais expressões alçam a categoria de deslizes morais, e qual o papel 
desses deslizes na identificação de fontes de injustiça e opressão e na ampliação das relações de reconhecimento. Procurase compreender como tais expressões são identificadas como ofensas morais, se elas contribuem para o reconhecimento ou se reforçam concepções cristalizadas de preconceito promovendo danos também na autoestima dos sujeitos.

Para tanto, na primeira seção, examinaremos como a visibilidade das identidades e das atitudes de intolerância é abordada pelas teorias do reconhecimento no sentido de descortinar consensos morais. A partir da ideia de deslize moral, discutir-se-á a centralidade do conceito para uma possível transformação moral da sociedade. Em seguida, apontamos para a necessidade de que essas questões não só se tornem públicas, mas sejam amplamente discutidas (MAIA, 2013; WARREN, 2006).

Na terceira parte analisaremos a repercussão de dois deslizes morais que circularam nos media em 2012. No primeiro deles, o jornalista J. R. Guzzo compara homossexuais a cabras e espinafres em texto publicado na revista Veja. No segundo, o colunista Walter Navarro, do jornal $O$ Tempo, de Belo Horizonte, ridiculariza a luta pela sobrevivência dos índios Guarani Kaiowá. Por fim, argumenta-se que os deslizes morais podem ser importantes para as lutas por reconhecimento dos sujeitos desde que eles estejam abertos à contestação pública e ao debate.

\section{A centralidade da visibilidade nas teorias do reconhecimento}

É consenso entre os autores das teorias do reconhecimento, nas suas mais variadas vertentes, que o desvelamento público de questões outrora invisibilizadas é condição fundante para a identificação de questões de opressão, para a superação destas e para 0 alargamento das relações de reconhecimento entre os sujeitos (GALEOTTI, 2002; HONNETH, 2003; MARKELL, 2003; TAYLOR, 1992). A despeito das inúmeras divergências entre tais teorias sobre 0 modo como a justiça deve ser alcançada e sobre o próprio conceito de reconhecimento, a necessidade de tornar visível e de lançar luz às injustiças é ponto pacífico entre elas. Discordam, entretanto, no modo como essas injustiças devem vir à tona.

Para Honneth, a visibilidade se revela num duplo movimento: 0 de constituição dos movimentos sociais; e o de desvelamento dos consensos morais com vistas à ampliação dos padrões de reconhecimento. 0 cerne da noção de lutas por reconhecimento se encontra na possibilidade que os sujeitos têm de nomear o sofrimento como injustiça por meio de um vocabulário comum, tornado público, que caracterize determinada situação como típica de um grupo inteiro. 0 compartilhamento de experiências, forte 0 suficiente para caracterizar uma identidade coletiva e os movimentos sociais, seria 0 que Honneth chamou de semântica coletiva 
(HONNETH, 2003). 0 desrespeito e a intolerância sofridos, quando compartilhados, descortinam e denunciam os consensos morais que guiam as concepções de justiça social.

Lançar luz às experiências individuais de sofrimento, tornando-as coletivas, aponta para a identificação de uma "lesão normativa desse consenso tacitamente efetivo" (HONNETH, 2003, p. 263), promovendo uma análise desse consenso moral que "regula de forma não oficial o modo como são distribuídos direitos e deveres entre dominantes e dominados" (HONNETH, 2003, p. 263). Ao questionar publicamente 0 pano de fundo que rege as relações sociais, os sujeitos alcançam a possibilidade, por meio da luta social, de instaurar novas gramáticas morais e relações de reconhecimento mais justas, que incluam o respeito às diferenças.

Taylor (1995) também aposta nesse descortinamento dos consensos morais na busca por reconhecimento intersubjetivamente construído. 0 autor trabalha com a ideia de desclosure, ou desvelamento, para o qual a condição de ser no mundo se daria a partir do trazer-à-luz. 0 desvelamento não seria uma ação individual, um sujeito ou objeto que espera ser descoberto, com impulsos intrapsíquicos de se apresentar ao outro, mas um processo que ocorre no espaço partilhado pelos seres humanos e que configura esses espaços.
Ainda que Taylor e Honneth defendam que 0 reconhecimento só pode ser alcançado quando diferentes modos de vida se tornam visíveis, eles acreditam também que 0 desrespeito e a ofensa desencadeiam danos às subjetividades dos sujeitos. Isso porque expressões de intolerância podem estimular uma "internalização da imagem da própria inferioridade" (TAYLOR, 1992, p. 44, tradução nossa) que se torna o instrumento mais poderoso da própria opressão.

Ele entende que o reconhecimento, tanto em Taylor quanto em Honneth, é a busca de um fim último, de um resultado com vistas à soberania, ao passo que o acknowledgment estaria no processo, na atividade política. 
a despertar expressões de desrespeito, mas também a possibilidade de transformação social. Markell defende a ideia de desclosure, baseado principalmente na obra de Arendt. 0 tornar público é, em si, um ato constitutivo da realidade social, pois lança o que estava oculto à condição de existência. 0 aparecer na cena pública traz a possibilidade de transformação social, sempre aberta e imprevisível, sujeita às contingências e vicissitudes da interação social, tais como conflito, hostilidade ou mal-entendidos (MARKELL, 2003).

Markell propõe um entendimento alternativo de justiça baseado não no reconhecimento de identidades, mas na reconfiguração da atitude de si mesmo diante do outro. A política do acknowledgement proposta por ele seria uma forma de reconciliação com o outro que envolve lidar com esses limites práticos impostos pela imprevisibilidade da ação humana, incluindo as expressões de intolerância.

A espontaneidade da interação social somada ao discurso da liberdade de expressão também é uma das premissas de Galeotti (2002, p. 147, tradução nossa) para explicar o surgimento e a possível aceitação de ofensas públicas. Para ela, considerar as injúrias como algo que traz prejuízos aos sujeitos é "uma matéria de incerteza inerente, e ainda intrinsecamente sempre contestável a priori". 0 que importa é que as diferenças se apresentem na esfera pública de modo a despertar tolerância e aceitação simbólica. Seria o primeiro passo para o pluralismo cooperativo, para a inclusão política dos sujeitos e para a atenuação das assimetrias de poder. No caso de expressões públicas de racismo, por exemplo, o que deve ser levado em conta é o resultado da ofensa e não a intenção. ${ }^{2}$

Efeitos nocivos concretos seriam a agressão física, a privação da liberdade e as atitudes abertas de discriminação nas quais são claras as distinções feitas com base na raça/cor, no acesso a direitos básicos. Independente da motivação, essas atitudes não devem ser toleradas, pois o desfecho implica numa violação óbvia dos direitos humanos. Já no caso de abuso verbal ou propagandas, a consequência pode ou não violar direitos humanos, pode ou não influenciar, por exemplo, na hora de contratar uma pessoa negra. "Na prática, é muito difícil traçar uma linha entre os possíveis riscos que devem, em teoria, surgir como resultado da propaganda e um risco real" (GALEOTTI, 2002, p. 146, tradução nossa).

A preocupação de Galeotti é com os possíveis limites da liberdade de expressão numa sociedade liberal com intervenção mínima do Estado. ${ }^{3}$ 
Embora este texto não tenha o objetivo de discutir o tema, é fato que uma maior ou menor exposição ao risco da intolerância reflete diretamente na possibilidade de problematização da questão, no reforço ao preconceito ou diluição deste. A contribuição da autora está na diferenciação entre racismo episódico, não problematizado por suas vítimas, e o racismo como problema político, no qual a percepção do risco e do dano aciona grupos alvo do racismo a "levantar suas vozes contra a opressão, discriminação e humilhação" (GALEOTTI, 2002, p.146, tradução nossa), ganhando ampla adesão social. A reação pública ao racismo revelaria que esse é um problema social e, por isso, deve ser levado em conta. É preciso que haja a percepção do risco, a identificação do racismo como assunto político e a problematização disso como dano real aos sujeitos. Assim, os deslizes morais que pretendemos investigar só ganham sentido como tal a partir da discussão pública.

Definimos como deslizes morais expressões públicas que revelam consensos enraizados no cotidiano e que soam ofensivas a determinados grupos, convocando a defesa de concepções de bem viver distintas daquelas tacitamente acordadas sob um pano de fundo moral valorativo. Ou seja, para ser considerado um deslize moral é preciso que determinada expressão carregue consigo uma tensão entre valores estabelecidos e valores que buscam se estabelecer como importantes na hierarquia moral. Para que essa tensão tenha alguma validade na ampliação das relações de reconhecimento defendemos que ela não apenas seja trazida a público, mas que desencadeie processos de debate que convoquem valores distintos.

Tully (2000) defende que as lutas por reconhecimento, na prática, são formas de buscar a participação política que envolve 0 processo argumentativo sempre aberto à revisão e à discordância. 0 exercício da liberdade política, coração da democracia, é o que as lutas devem buscar. Ele utiliza os termos desclosure e acknowledgment para identificar os processos de desvelamento dos modos distintos de vida, que levam à contestação de normas intersubjetivas. Ainda que a resposta às diferenças seja negativa, como nos casos dos deslizes morais veiculados pelos media, ela se revela uma forma de desencadear o diálogo, de dissipar o ressentimento, de empoderar grupos oprimidos e de superar os efeitos psicológicos e sociais gerados pelo não-reconhecimento (TULLY, 2000).

0s deslizes morais desencadeariam, assim, não uma luta pelo reconhecimento de uma minoria, mas uma luta acerca do reconhecimento, reconfigurando mutuamente toda a comunidade política e, em última análise, as próprias identidades. É uma demanda por outra ordem de reconhecimento. Ao mesmo tempo em que desvela identidades, as faz reconhecida, lança novas demandas de reconhecimento que são sucessivamente transformadas pelo dialogismo e pela interação, próprios da natureza das lutas (TULLY, 2000). 
Logo, uma concepção deliberativa e discursiva do reconhecimento (MAIA, 2013; MENDONÇA, 2011; MENDONÇA; MAIA, 2009; TULLY, 2000), coloca 0 debate público como uma dimensão central das lutas por reconhecimento. 0s deslizes morais de que tratamos aqui só revelam consensos tácitos e prejuízos morais na medida em que desencadeiam a discussão pública. Ainda que os autores do reconhecimento discordem sobre os efeitos gerados a partir das ofensas, concordam que a expressão pública das injustiças exerce a função de desvelar injustiças e denunciar consensos normativos.

\section{0 debate como condição para novas gramáticas morais}

Preconceitos em relação a grupos como índios ou gays, ainda que impliquem certo constrangimento para apresentação pública, estão difundidos no cotidiano das pessoas. As teorias deliberacionistas defendem, de maneira geral, a necessidade de mobilizar de forma crítica a sociedade. Para tanto, é necessário chamar os cidadãos à discussão e estimular a reflexão, 0 que pode resultar na desestabilização discursos cristalizados. Para desestruturar formas de entendimento enraizadas na vida das pessoas é preciso chamá-las à discussão e dialogar com seus entendimentos de mundo, ancorados em consensos morais tácitos.

Contudo, o debate público também pode implicar riscos para as lutas por reconhecimento. Alguns autores acreditam que nem sempre a deliberação é a saída para resolução de problemas controversos. Bell (1999) afirma que o processo deliberativo pode ser contraproducente já que há a possibilidade de intensificar o desacordo. 0 autor defende que em alguns casos "apenas" discutir pode levar a lugar nenhum. Assim, uma medida mais eficaz para a defesa de políticas com foco nas pessoas excluídas talvez fosse colocar a questão de forma impositiva e sem muita abertura à discussão. Nesse sentido, podemos pensar na construção de leis, como a relativa à criminalização da homofobia.

De forma complementar, Simon (1999) afirma que a deliberação pode ser uma "perda de tempo" porque os sujeitos não estariam predispostos à reflexão. Garantir espaço para posicionamentos preconceituosos pode incorrer no risco de promover razões para os que justificam como legítimo o preconceito contra gays e índios, por exemplo. Medearis (2004) também afirma que, em determinadas questões, não faz mesmo sentido ouvir a voz dos "maus", já que geralmente são eles que representam posições cristalizadas e possuem poder.

Se, por um lado, a deliberação envolve tensões e riscos, por outro, evitar o confronto e a manifestação pública do preconceito não é suficiente para eliminálo. Dryzek (2000, p. 160, tradução nossa) argumenta que: "Um modelo de democracia deliberativa que dá ênfase à contestação de discursos na esfera pública permite desafiar as posições sectárias, assim como todo tipo de discurso opressivo". Dryzek (2000, p. 168, tradução nossa) afirma também que, não é 
necessário censurar discursos de antemão em nome do que seria "politicamente correto", já que o mais importante seria "transmitir, o mais longe possível, mecanismos endógenos à própria deliberação para transformar visões e atitudes numa direção benigna".

Também Gomes (2001, p. 12) aposta no embate entre discursos como aquele capaz de definir 0 que é moralmente válido e passível de expressão. Para ele, se admitirmos a dignidade humana como único valor absoluto, a liberdade de expressão

é legítima eticamente apenas enquanto o seu exercício não produzir atos cujos efeitos sejam contrários à dignidade dos outros. [...] Pode acontecer de um ato singular de livre expressão ser perfeitamente imoral. São dessa natureza, certamente, as publicações e os atos de fala ofensivos, infames, difamatórios e humilhantes.

A principal questão é: se esses discursos devem ser evitados, a quem cabe o juízo sobre o que é moralmente válido? Para Gomes (2001, p. 16), 0 juízo de valor, "só é válido quando a norma que 0 orienta tiver sido objeto de discurso prático". Assim, o que deve ou não ser publicado deve ser o próprio objeto de discussão. A própria definição do que é um deslize ou do que é politicamente correto só pode ser alcançada por meio do debate.

0 problema é quando expressões de intolerância simplesmente desconsideram de antemão os argumentos daquele que é alvo da ofensa. Para Warren (2006), alguns temas podem gerar insultos públicos que resultam ou agravam as desigualdades visto que subjugam a validade dos argumentos de outros. São assuntos em que "o que do proferimento diz diretamente do quem do interlocutor". Em uma discussão sobre homofobia entre uma pessoa homofóbica e outra que se apresenta como gay, se a primeira manifesta preconceito a respeito da segunda, ela está falando diretamente sobre uma característica do interlocutor. Com isso, ele pode desconsiderar de antemão os argumentos do participante gay, simplesmente pelo fato de ser gay, o que minaria a possibilidade de troca deliberativa.

Como solução, Warren (2006) propõe duas possibilidades: a diplomacia deliberativa e 0 agonismo deliberativo. A primeira busca criar um terreno de entendimento mínimo onde a troca de argumentos sobre temas sensíveis não acabe com a possibilidade de discussão entre os interlocutores. Seria o mínimo de boas maneiras, o que pode garantir o reconhecimento necessário ao processo deliberativo quando as condições do discurso estão muito longe de serem as ideais. 0 contraponto é 0 agonismo deliberativo, no qual o melhor seria a expressão sincera de todos os argumentos envolvidos no assunto para que se provocasse um abalo em falsos consensos. No entanto, Warren (2006) alerta que a abertura pública a posicionamentos preconceituosos pode ser difícil de ser "consertada" e que a deliberação agonista só faria sentido onde a cultura de direitos estivesse segura. Essa proposição está bem próxima dos riscos apontados por Bell (1999), Medearis (2004) e Simon (1999) e, de certa forma, distante da ideia de Dryzek (2000) de que 
não deve haver proibição de proferimentos públicos e, sim, o reforço aos mecanismos endógenos à deliberação para mudança de valores e crenças em um sentido benigno.

Cabe aqui retomar a indagação inicial: a ofensa pública pode contribuir com lutas por reconhecimento ou acaba por reforçar injustiças? A partir da análise dos casos empíricos tentaremos lançar luz sobre a questão.

\section{Procedimentos metodológicos}

Os casos analisados tiveram grande repercussão em novembro de 2012 na internet. No primeiro, o jornalista J. R. Guzzo compara homossexuais a cabras em texto publicado na revista Veja e, no segundo, o colunista Walter Navarro, na versão on-line do jornal 0 Tempo, de Belo Horizonte, ridiculariza a luta pela sobrevivência dos índios Guarani Kaiowá. Embora sejam veículos de expressões diferentes - uma revista de circulação nacional e um jornal regional on-line - os dois textos são provenientes de colunas já consolidadas, escritas por colunistas de destaque em seus veículos, com forte componente autoral.
Como procedimento de coleta de dados realizamos uma pesquisa exploratória sobre os debates nas redes sociais (Facebook e Twitter) acerca dos dois artigos. Identificamos que a maioria das postagens e comentários remetia a blogs que já haviam se posicionado sobre os temas. A partir disso, mapeamos os blogs nas duas semanas subsequentes à publicação dos artigos. As reações ao artigo da Veja foram coletadas pelas palavras-chave combinadas "cabra" e "gay", e pelo título da coluna Parada gay, cabra e espinafre. Foram encontrados 34 blogs (27 textos autorais, 4 reproduções do texto da Veja e 3 reproduções da resposta do deputado Jean Wyllys à Veja). Dentre os textos autorais, dois defendem o posicionamento de Guzzo e 25 0 criticam. Os comentários analisados foram extraídos dos cinco blogs mais comentados:

As reações ao texto de Navarro, pelo próprio alcance do jornal $O$ Tempo e pelo pouco tempo que ficou no ar, foram menores em número em relação às reações ao texto da Veja. Utilizando as palavras-chave "Walter Navarro", "índio", "guarani kaiowá", "jornal 0 Tempo", fizemos a busca com 0 filtro para blogs nas duas semanas investigadas.

Quadro 1: Blogs analisados - Caso Guzzo

\begin{tabular}{|c|c|c|}
\hline Blog & Quantidade de comentários & Posicionamento \\
\hline Perca Tempo & 275 & \multirow{2}{*}{ Reproduz o texto da Veja } \\
\hline Blog do Miro & 197 & \multirow{2}{*}{ Contra 0 artigo } \\
\hline Jean Wyllys (deputado federal) & 469 & \\
\hline Escreva Lola, escreva & 166 & \\
\hline Carlos Orsi & 260 & \\
\hline
\end{tabular}

Fonte: Dados da pesquisa. 
Encontramos 12 textos em 10 blogs, sendo que um deles reproduzia a coluna na íntegra, outro reproduzia a crítica do blog BHaz e os outros eram autorais. As análises dos comentários foram feitas nos dois blogs mais comentados: Tropa dos Lanternas Verdes (89 comentários) $)^{4}$ e BHaz (175). ${ }^{5}$

Consideramos os argumentos utilizados pelos colunistas, blogueiros e comentadores dos blogs com o objetivo de identificar: a) quais os consensos morais e valores refletidos por eles; $b$ ) se procuram confirmar consensos ou descortinar injustiças; c) se promovem uma ampliação das injúrias, reforçando o preconceito.

\section{Deslizes morais: a ofensa pública}

A edição de Veja de 14 de novembro de 2012 dedicou três páginas à coluna de J. R. Guzzo. Ao defender a liberdade de expressão, Guzzo (2012, p. 117) diz que não é crime dizer que não gosta de gays, visto que a lei "não obriga nenhum cidadão a gostar de homossexuais, ou de espinafre, ou de seja lá o que for".

0 colunista defende ainda que 0 casamento só existe entre homens e mulheres porque geram filhos, mas que qualquer pessoa pode ter um relacionamento com quem quiser. "Um homem também não pode se casar com uma cabra, por exemplo; pode até ter uma relação estável com ela, mas não pode se casar" (GUZZ0, 2012, p.117). As comparações foram vistas como uma forma de "coisificar e desumanizar" os gays, extraindo-lhes a generalidade humana. (MACHAD0, 2012) A Veja não se posicionou sobre 0 assunto.

No caso da edição on-line de $O$ Tempo, publicada em 8 de novembro de 2012, 0 texto tentou fazer uma crítica irreverente sobre as manifestações nas redes sociais em favor dos índios Guarani Kaiowá, mas acabou ridicularizando o drama dos indígenas. A coluna de Navarro, intitulada Guarani Kaiowá é o c... Meu nome agora é Enéas p ..., teve repercussão negativa, culminando na retirada do artigo do ar e no afastamento do colunista cinco dias depois.

Navarro zomba da mobilização nas redes sociais, chamando quem se envolveu de "ambientalistas de Facebook" e partidários dos "Espelhinhos \& Miçangas". 0 ponto de maior controvérsia foi a frase "índio bom é índio morto":

Tem coisa mais chata, hipócrita, brega e programa de índio que este pessoal do Facebook adotando o nome Guarani Kaiowá? [...] Uma dessas chatas do Facebook reclamou da minha gozação dizendo que todo brasileiro é guarani kaiowá. Eu não! [...] Como diriam o Marechal Rondon e os irmãos Villas Boas, "Índio bom é índio morto"! "Matar, se preciso for, morrer, nunca!" (NAVARR0, 2012, p. 1). 
0 colunista ridiculariza o modo de vida dos índios, concluindo que a "vadiagem dos guarani kaiowá pelo menos é lucrativa", já que ele conseguiu trocar um canivete suíço falso por várias toras de mogno.

Pigmeus, parecem formigas gigantes e caracterizam-se pela insuportável pneumatose intestinal, o que faz deles companhia deveras desagradável. [...] Por isso, o Brasil é assim, uma mistura de índios flatulentos com criminosos portugueses [...] (NAVARR0, 2012, p. 1).

Diferente do texto da Veja, argumentativo do início ao fim, a natureza do de Navarro se alinha a uma sátira. Nas redes sociais 0 texto foi entendido como ofensa e incentivo ao ódio. Nos dois casos há, de saída, uma desqualificação não só das demandas, mas da própria existência desses dois grupos sociais ("ser gay" e "ser índio" eram o próprio objeto da ofensa). Esse tipo de argumentação, defende Warren (2006), pode minar o debate na medida em que desconsidera o "quem" do interlocutor, embora, como Warren aponta, a manifestação agonística dos posicionamentos pode ser a alavanca para modificar preconceitos e posições enraizadas socialmente. A análise dos casos mostra que a ofensa desencadeou 0 debate. Se no caso dos homossexuais, muitos falaram por si mesmos, no caso dos indígenas, nenhum se identificou como afetado direto. Ainda assim, houve uma mobilização a favor deles. Os movimentos sociais também tiveram importante papel de contestação.

\section{0 tensionamento dos consensos tácitos}

0 debate público mediado que se instaurou a partir do texto de Guzzo acionou vários argumentos, pedidos de resposta por parte dos movimentos sociais, bem como acusações e ofensas mútuas. Dentre elas, a de que o texto da Veja foi mal compreendido, que as comparações com cabras e espinafre são apenas exemplos didáticos, que houve distorção dos dados ou uso de "má fé" ou "desonestidade intelectual". Jogos de retórica à parte, apontamos três principais consensos enraizados no tecido social mobilizados pelo texto de Guzzo e os argumentos favoráveis e contra 0 artigo da Veja que tensionam esses entendimentos.

0 primeiro está ligado à ideia da homossexualidade ser uma questão privada e, portanto, uma escolha, "um estilo de vida gay" individual, o que invalidaria a própria existência do movimento LGBT. Segundo Guzzo (2012, p. 116), o esforço de reduzir 0 homossexualismo à sua verdadeira natureza, "uma questão estritamente pessoal", não estaria tendo sucesso: "0 primeiro problema sério quando se fala em 'comunidade gay' é que a 'comunidade gay' não existe - e também não existem, em consequência, o 'movimento gay' ou suas 'lideranças".

Entre os argumentos que reforçam esse consenso tácito, alguns blogs defendem que a questão da homossexualidade é restrita ao ato sexual em si e a uma questão de escolha. "Assim como 
há libélulas que decidem, voluntariamente, deixar de ser gays há machões que, um belo e florido dia, resolvem sair do armário" (GUSTAVO, 2012).

Tal consenso moral é desafiado por argumentos que defendem a existência de uma comunidade LGBT composta de pessoas diferentes, mas que "partilham um sentimento de pertencer a um grupo cuja base de identificação é ser vítima da injúria, da difamação e da negação de direitos" (WYLLYS, 2012). Essa pertença faz gerar "a vontade de agir politicamente em nome do coletivo", de onde nasce o movimento LGBT. Muitos blogs defendem o argumento de que 0 sentimento de pertença é o mesmo que move as lutas dos negros, das feministas e que forma comunidades como associações de bairro ou classes sindicais. Outro argumento é que Guzzo reproduz o discurso conservador que credita sucessos e fracassos a indivíduos, sem considerar a história de luta, os contextos e condições sociais (ARONOVICH, 2012).

Defende-se que as conquistas dos homossexuais foram fruto da luta e não um "avanço natural das sociedades no caminho da liberdade", como diz Guzzo. 0 discurso do indivíduo seria uma tentativa de enfraquecer o coletivo.

São apontados, em outros blogs, problemas sociais originados do não reconhecimento dos homossexuais, como o respeito ao nome social dos travestis e transexuais, a liberdade de expressão de afeto em público, discriminação no mercado de trabalho, dentre outras.
0 segundo ponto de grande controvérsia foi a afirmação de Guzzo de que a homofobia não existe e que seria uma "campanha contra preconceitos imaginários e por direitos duvidosos" (GUZZO, 2012, p. 117). Nesse sentido, a criminalização da homofobia seria desnecessária, pois, para ele, qualquer tipo de violência já está previsto na lei brasileira, que não pode obrigar ninguém a gostar de homossexuais, espinafres, ou seja lá o que for.

Na mesma linha, o blog Do Contra, ao criticar o posicionamento do deputado Jean Wyllys, aponta que a criminalização da homofobia seria um passo para impor a obrigação de gostar de gays. A suposta existência da homofobia "faz parte do discurso da vitimização gayzista". 0 número de 300 assassinatos por ano seria um "número irrisório, menos de 0,001\% do total". E conclui que Jean Wyllys "jamais vai admitir o óbvio: que não somos homofóbicos" (GUSTAV0, 2012).

Argumentos contrários apontam que os dados são referentes estritamente a crimes de ódio por causa da orientação sexual, revelando-se altos; que pesquisas indicam que a maioria dos crimes acontece dentro de casa, sendo de difícil mensuração; que a violência contra gays não se resume a homicídios e que gays não querem ser gostados, mas respeitados. "Não se vê por aí pessoas apanhando por serem héteros. Nunca li sobre estupro corretivo em mulheres heterossexuais. Nenhum filho é expulso de casa por ser hétero" (GOES, 2012). 
Por fim, o terceiro consenso moral trata da impossibilidade de casamento entre pessoas do mesmo sexo. "A lei não pode (nem deve) ser modificada para satisfazer a agenda política de um 'movimento', ainda mais um cujo critério de existência é tão subjetivo" (GUSTAVO, 2012).

A comparação entre gays e cabras feita por Guzzo foi o ponto mais criticado nas redes sociais. Um argumento contrário versa sobre a atual estrutura familiar e a lógica da reprodução. "Faz pelo menos cem anos que 0 objetivo do casamento não é a geração de filhos. Caso contrário, casais héteros que não podem ter filhos (como velhinhos, por exemplo) teriam que se separar" (GOES, 2012).

Defendeu-se que 0 casamento entre pessoas do mesmo sexo seria também uma garantia igualitária de direitos e que as tais uniões passaram a ser consideradas famílias desde a decisão do STF em 2011. 0 argumento acatado pelo Supremo é que 0 fato de a lei falar que 0 casamento é entre um homem e uma mulher "não significa que a lei teria proibido o casamento entre pessoas do mesmo sexo, mas apenas que regulamentou 0 casamento heteroafetivo sem proibir 0 casamento homoafetivo" (VECCHIATTI, 2012).

0 principal consenso moral acionado pelo artigo de Navarro foi o que versa sobre o modo de vida dos indígenas considerados preguiçosos, flatulentos, desonestos e libidinosos. A argumentação girou apenas em torno do reconhecimento ou não da cultura indígena e de suas demandas: "por que os índios não podem beber, trabalhar, pagar impostos? Eles não são brasileiros como nós? [...] E, sim, há a possibilidade de eles terem a cultura deles preservada ao mesmo tempo em que colaboram pelo crescimento do país" (NAVARR0, 2012, p. 1).

A desonestidade dos indígenas foi outro argumento contra o reconhecimento das demandas deles. Foram acusados de "venderem as suas terras a preço de banana para os grandes fazendeiros" e de contrabandearem madeira ilegal, segundo comentários do blog BHaz. Enquanto seus defensores apoiam a liberdade de expressão e confirmam a desvalorização dos modos de vida dos índios considerando-os preguiçosos e desonestos, os argumentos contrários, salvo poucas exceções, acusam Navarro de crime de ódio, incentivo ao genocídio e humilhação pública. 0 debate não versa sobre a necessidade de desvelar entendimentos cristalizados sobre a cultura indígena. Apenas um comentário procura tensionar o imaginário de que índios são preguiçosos e indignos de respeito: "Dizer que 0 índio é atrasado é ter um posicionamento anacrônico, pois sua concepção de vida e de sociedade é diferente da nossa" (FEDERICI, 2012).

0 blog BHaz linkou uma carta assinada por organizações da sociedade civil, que aponta 0 artigo como uma irresponsabilidade que agrava ainda mais a situação dos indígenas, vítimas de assassinato e "confinados em reservas superlotadas, sem acesso a recursos básicos, ou relegados a viverem à beira de estradas, sob 
barracas de lona, perseguidos por fazendeiros e pistoleiros no Mato Grosso do Sul".

\section{Considerações finais}

0 objetivo deste artigo foi problematizar, à luz de dois casos empíricos, a relação entre ofensas públicas e lutas por reconhecimento. Observamos que os deslizes morais publicados na Veja e no Tempo revelaram consensos tácitos que desqualificam o modo de vida de gays e índios. Muitos comentadores dos blogs afirmaram que os colunistas disseram "aquilo que muita gente queria dizer, mas não tinha coragem", revelando assim que a origem das ofensas públicas está pano de fundo moral que retroalimenta os fenômenos mediáticos. 0s deslizes morais são, assim, inescapáveis à mídia e fazem parte da imprevisibilidade decorrente das interações sociais. Acreditamos, tal como Galeotti (2002), Markell (2003) e Tully (2000) que essa a imprevisibilidade pode fazer com que as injúrias revelem opressões veladas e desencadeiem lutas por reconhecimento e oportunidades para corrigir mal-entendidos. Não se trata de defender a liberdade de ofensa pública, mas a existência de uma incontrolabilidade da expressão pública.

0 tensionamento de valores, entretanto, se deu de maneira distinta em um e outro caso. Ambos foram considerados como ofensas públicas e discriminação, mas também foram defendidos com 0 argumento da liberdade de expressão. A diferença é que no caso de Navarro o crime de ódio, previsto em lei, é constantemente citado, em referência à frase: índio bom é índio morto. Isso faz com que o deslize moral em questão ganhe a conotação de um crime. Ainda que 0 incentivo à morte dos índios seja uma expressão de intolerância grave, ela despertou apenas repulsa, indignação e reivindicações de punição. Quase nada se argumentou sobre porque o modo de vida dos índios é digno de valor e reconhecimento.

A existência do debate não confirma, é claro, a mudança da percepção sobre os homossexuais, mas ao menos problematiza publicamente porquê eles buscam ser reconhecidos. Consideramos que essa diferença no percurso do debate deve-se também ao grau de organização do movimento LGBT e, com isso, a maior capacidade de construírem pontes semânticas e enquadrarem 0 artigo como deslizes morais. A compreensão de bem viver dos índios requer muito mais a construção de novos parâmetros valorativos, uma fusão de horizontes (TAYLOR, 1992), diferente da compreensão de evolução das sociedades urbanas.

É claro que em outros casos, ofensas não são sequer problematizadas e podem trazer muito mais danos do que oportunidades de debate, prejuízos, inclusive, às próprias identidades dos sujeitos (HONNETH, 2003; TAYLOR, 1992). Coibir expressões de desrespeito, contudo, pode contribuir para constranger posicionamentos públicos dessa natureza e velar entendimentos tácitos (DRYZEK, 2000), gerando debates 
superficiais, em nome das boas maneiras (WARREN, 2006).

Os deslizes morais, ainda que não desejados pela possibilidade de causar danos aos sujeitos, podem criar uma abertura para a reflexão pública ao desvelar consensos tácitos e colocá-los em discussão, o que poderia levar ao questionamento mais agonístico dos preconceitos e estimular a construção de um terreno mais sólido para 0 reconhecimento como autorrealização.

\section{Referências}

ARONOVICH, Lola. Artigo na Veja sobre gays, espinafre e cabras me deixou cabreira.

2012. Disponível em: http://escrevalolaescreva. blogspot.com.br/2012/11/artigo-na-veja-sobregays-espinafre-e.html

BELL, Daniel. Democratic Deliberation: the problem of implementation. In: MACED0, Stepfen (Ed.). Deliberative Politics: essays on Democracy and Disagreement. Nova Iorque: Oxford University Press, 1999. p. 70-87.

DRYZEK, John. Deliberative Democracy and Beyond: Liberals, Critics, Contestations. Nova Iorque: Oxford, 2000.

FEDERICI, Cesar Gaglioni. Guarani-Kaiowá, Walter Navarro e a estupidez. 2012. Disponível em: < http://tropalanternaverde.blogspot.com. br/2012/11/guarani-kaiowa-walter-navarro-e.html>

\section{GALEOTTI, Anna. Toleration as Recognition.}

Cambridge: Cambridge University Press, 2002.

GOES, Tony. Cabra marcada para morrer. 2012.

Disponível em: < http://tonygoes.blogspot.com. br/2012/11/cabra-marcada-para-morrer.html>

GOMES, Wilson. Opinião política na Internet: uma abordagem das questões relativas a censura e liberdade de expressão na comunicação em rede. In: ENCONTRO ANUAL DA COMPÓS, 10., 2001. Brasília. Anais... Brasília, 2001.

GUSTAVO. De gays, cabras e asnos. 2012. Disponível em: <http://gustavo-livrexpressao.blogspot.com. br/2012/11/de-gays-cabras-e-asnos.html>

GUZZO, J. R. Parada gay, cabras e espinafre. Veja, São Paulo, n. 2295, 14 nov. 2012, p. 116-118.

\section{HONNETH, Axel. Luta por reconhecimento:} a gramática moral dos conflitos sociais. São Paulo: Ed. 34, 2003.

MACHAD0, Thiago. Tolerância aos intolerantes? Ser gay ou não ser, eis a questão! 2012. Disponível em: <http://www.espacobanal.com.br/2012/11/ tolerancia-aos-intolerantes-ser-gay-ou.html>

MAIA, Rousiley. Deliberation, the Media and

Political Talk. Hampton Press, 2012. Recognition and Media. Londres: Palgrave Macmillan, 2013. No prelo. 
MARKELL, Patchen. Bound by Recognition.

Princeton: Princeton University Press, 2003.

MEDEARIS, John. Social Movements and

Deliberative Democratic Theory. British Journal

of Political Science, n. 35, p. 53-75, 2004

MENDONÇA, Ricardo F. Reconhecimento e (qual?) deliberação. Opinião Pública, Campinas, v. 17, n. 1, p. 206-227, jun. 2011.

MENDONÇA, Ricardo F; MAIA, Rousiley. Poderia a deliberação enriquecer o reconhecimento?

Revista FAMEC0S, v. 1, p. 70-77, 2009.

MIGUEL, Luis Felipe. Rafinha e a calcinha: a

liberdade de expressão, seus limites e os limites do limites. In: ENCONTRO ANUAL DA COMPÓS, 21., 2012. Juiz de Fora. Anais... Juiz de Fora, 2012.

NAVARR0, Walter. Guarani Kaiowá é o c... Meu nome agora é Enéas p... Jornal 0 Tempo, 08 nov. 2012.

SIMON, William. Tree Limitations of Deliberative Democracy: identity politics, bad faith and indeterminacy. In: MACEDO, Stepfen (Ed.). Deliberative Politics: essays on Democracy and Disagreement. Nova Iorque: Oxford University Press, 1999. p. 49-57.

TAYLOR, Charles. El multiculturalismo y "la política del reconocimiento. México: Fondo de Cultura Económica, 1992. . Argumentos filosóficos. Tradução de Adail Ubirajara Sobral. São Paulo: Loyola, 1995.

TULLY, James. Struggles over Recognition and Distribution. Constellations, v. 7, n. 4, p. 469$482,2000$.

VECCHIATTI, Paulo Roberto Iotti. Veja que exemplo de mau jornalismo. 2012. Disponível em: $<$ http://pauloriv71.wordpress.com/2012/11/16/vejaque-exemplo-de-mau-jornalismo/>

WARREN, Mark. What should and should not be said: Deliberating Sensitive Issues. Journal of Social Philosophy, v.37, n. 2, p.163-181, 2006.

WYLLYS, Jean. Veja que lixo! 2012. Disponível em: < http://jeanwyllys.com.br/wp/veja-que-lixo > 
Moral lapses in the media scene: Reproduction of intolerance or opportunity for new moral grammars?

\section{Abstract}

The paper discusses how moral lapses conveyed in the media reinforce prejudices or reveal little themed issues in the public sphere. What is the role of these moral lapses in the expansion of relations of recognition and transformation of moral grammars that govern society? From an approximation between theories of recognition and deliberation, we analyze the impact of Internet in two articles: one about the gay movement, by JR Guzzo, published in Veja Magazine, and another on the Guarani Kaiowá, published by the Walter Navarro on the online version of the diary 0 Tempo. The analysis took into account a) the unveiling of tacit consensus and b) the possibility of discussion of values in order to expand moral grammars.

\section{Keywords}

Moral Lapses. Recognition. Public Debate.

\section{Lapsos morales en la escena mediática: ¿La reproducción de la intolerancia o la nueva oportunidad para las gramáticas morales?}

\section{Resumen}

Se discute cómo lapsos morales transmitidos en los medios de comunicación pueden reforzar los prejuicios o revelar cuestiones que aparecen rara vez en la esfera pública. ¿Cuál es el papel de estos lapsos morales en la expansión de las relaciones de reconocimiento y la transformación de las gramáticas morales que rigen la sociedad? Por medio de una articulación entre las teorías del reconocimiento y de la deliberación, buscamos analizar el impacto de dos artículos en la internet: uno sobre el movimiento gay, de J.R. Guzzo, publicado en la revista Veja, y otro artículo respecto a los indios Guaraní Kaiowá, publicado por Walter Navarro en la versión online del periódico 0 Tempo. El análisis tuvo en cuenta: a) la presentación de un consenso tácito y b) la posibilidad de discusión de valores con el fin de ampliar las gramáticas morales.

\section{Palabras-clave}

Lapsos morales. Reconocimiento. Debate público. 


\section{Expediente}

A revista E-Compós é a publicação científica em formato eletrônico da Associação Nacional dos Programas de Pós-Graduação em Comunicação (Compós). Lançada em 2004, tem como principal finalidade difundir a produção acadêmica de pesquisadores da área de Comunicação, inseridos em instituições do Brasil e do exterior.

\section{E-COMPÓS I www.e-compos.org.br I E-ISSN 1808-2599}

Revista da Associação Nacional dos Programas

de Pós-Graduação em Comunicacão.

Brasília, v.16, n.2, maio/ago. 2013

A identificação das edições, a partir de 2008

passa a ser volume anual com três números.

\section{CONSELHO EDITORIAL}

Afonso Albuquerque, Universidade Federal Fluminense, Brasil Alberto Carlos Augusto Klein, Universidade Estadual de Londrina, Brasil Alex Fernando Teixeira Primo, Universidade Federal do Rio Grande do Sul, Brasil Ana Carolina Damboriarena Escosteguy, Pontifícia Universidade Católica do Rio Grande do Sul, Brasi

Ana Gruszynski, Universidade Federal do Rio Grande do Sul, Brasil Ana Silvia Lopes Davi Médola, Universidade Estadual Paulista, Brasil André Luiz Martins Lemos, Universidade Federal da Bahia, Brasil Ângela Freire Prysthon, Universidade Federal de Pernambuco, Brasil Antônio Fausto Neto, Universidade do Vale do Rio dos Sinos, Brasil Antonio Carlos Hohlfeldt, Pontifícia Universidade Católica do Rio Grande do Sul, Brasil Antonio Roberto Chiachiri Filho, Faculdade Cásper Líbero, Brasil Arlindo Ribeiro Machado, Universidade de São Paulo, Brasil Arthur Autran Franco de Sá Neto, Universidade Federal de São Carlos, Brasil Benjamim Picado, Universidade Federal Fluminense, Brasil

César Geraldo Guimarães, Universidade Federal de Minas Gerais, Brasil Cristiane Freitas Gutfreind, Pontifícia Universidade Católica do Rio Grande do Sul, Brasil Denilson Lopes, Universidade Federal do Rio de Janeiro, Brasi Denize Correa Araujo, Universidade Tuiuti do Paraná, Brasil Edilson Cazeloto, Universidade Paulista , Brasi Eduardo Peñuela Cañizal, Universidade Paulista, Brasil Eduardo Vicente, Universidade de São Paulo, Brasil Eneus Trindade, Universidade de São Paulo, Brasi Erick Felinto de Oliveira, Universidade do Estado do Rio de Janeiro, Brasi Florence Dravet, Universidade Católica de Brasilia, Brasil Francisco Eduardo Menezes Martins, Universidade Tuiuti do Paraná, Brasil Gelson Santana, Universidade Anhembi/Morumbi, Brasil Gilson Vieira Monteiro, Universidade Federal do Amazonas, Brasil Gislene da Silva, Universidade Federal de Santa Catarina, Brasil Guillermo Orozco Gómez, Universidad de Guadalajara

Gustavo Daudt Fischer, Universidade do Vale do Rio dos Sinos, Brasil Hector Ospina, Universidad de Manizales, Colômbia

Herom Vargas, Universidade Municipal de São Caetano do Sul, Brasi leda Tucherman, Universidade Federal do Rio de Janeiro, Brasil Inês Vitorino, Universidade Federal do Ceará, Brasil Janice Caiafa, Universidade Federal do Rio de Janeiro, Brasil Jay David Bolter, Georgia Institute of Technology Jeder Silveira Janotti Junior, Universidade Federal de Pernambuco, Brasil João Freire Filho, Universidade Federal do Rio de Janeiro, Brasil John DH Downing, University of Texas at Austin, Estados Unidos
José Afonso da Silva Junior, Universidade Federal de Pernambuco, Brasi José Carlos Rodrigues, Pontifícia Universidade Católica do Rio de Janeiro, Brasi José Luiz Aidar Prado, Pontifícia Universidade Católica de São Paulo, Brasil José Luiz Warren Jardim Gomes Braga, Universidade do Vale do Rio dos Sinos, Brasil Juremir Machado da Silva, Pontifícia Universidade Católica do Rio Grande do Sul, Brasil Laan Mendes Barros, Universidade Metodista de São Paulo, Brasil Lance Strate, Fordham University, USA, Estados Unidos Lorraine Leu, University of Bristol, Grã-Bretanha Lucia Leão, Pontifícia Universidade Católica de São Paulo, Brasil Luciana Panke, Universidade Federal do Paraná, Brasil Luiz Claudio Martino, Universidade de Brasília, Brasil Malena Segura Contrera, Universidade Paulista, Brasil Márcio de Vasconcellos Serelle, Pontifícia Universidade Católica de Minas Gerais, Brasil Maria Aparecida Baccega, Universidade de São Paulo e Escola Superior de Propaganda e Marketing, Brasil

Maria das Graças Pinto Coelho, Universidade Federal do Rio Grande do Norte, Brasil Maria Immacolata Vassallo de Lopes, Universidade de São Paulo, Brasil Maria Luiza Martins de Mendonça, Universidade Federal de Goiás, Brasi Mauro de Souza Ventura, Universidade Estadual Paulista, Brasil

Mauro Pereira Porto, Tulane University, Estados Unidos Nilda Aparecida Jacks, Universidade Federal do Rio Grande do Sul, Brasi Paulo Roberto Gibaldi Vaz, Universidade Federal do Rio de Janeiro, Brasi Potiguara Mendes Silveira Jr, Universidade Federal de Juiz de Fora, Brasi Renato Cordeiro Gomes, Pontifícia Universidade Católica do Rio de Janeiro, Brasil Robert K Logan, University of Toronto, Canadá

Ronaldo George Helal, Universidade do Estado do Rio de Janeiro, Brasil Rosana de Lima Soares, Universidade de São Paulo, Brasi Rose Melo Rocha, Escola Superior de Propaganda e Marketing, Brasil Rossana Reguillo, Instituto de Estudos Superiores do Ocidente, Mexico Rousiley Celi Moreira Maia, Universidade Federal de Minas Gerais, Brasi Sebastião Carlos de Morais Squirra, Universidade Metodista de São Paulo, Brasil Sebastião Guilherme Albano da Costa, Universidade Federal do Rio Grande do Norte, Brasil

Simone Maria Andrade Pereira de Sá, Universidade Federal Fluminense, Brasi Tiago Quiroga Fausto Neto, Universidade de Brasília, Brasil Suzete Venturelli, Universidade de Brasília, Brasil Valério Cruz Brittos, Universidade do Vale do Rio dos Sinos, Brasil Valerio Fuenzalida Fernández, Puc-Chile, Chile

Veneza Mayora Ronsini, Universidade Federal de Santa Maria, Brasi Vera Regina Veiga França, Universidade Federal de Minas Gerais, Brasil

\section{COMISSÃO EDITORIAL}

Adriana Braga I Pontifícia Universidade Católica do Rio de Janeiro, Brasi

Felipe Costa Trotta I Universidade Federal Fluminense, Brasi CONSULTORES AD HOC

Alexandre Barbalho, Universidade Estadual do Ceará, Brasil

Ana Carolina Escosteguy, Pontifícia Universidade Católica do Rio Grande do Sul, Brasi

Ana Gruszynski, Universidade Federal do Rio Grande do Sul, Brasi

Arthur Ituassu, Pontifícia Universidade Católica do Rio de Janeiro, Brasil

Claudia Lahni, Universidade Federal de Juiz de Fora, Brasil

Francisco Paulo Jamil Marques, Universidade Federal do Ceará, Brasil

Jiani Bonin, Universidade do Vale do Rio dos Sinos, Brasil

José Luiz Braga, Universidade do Vale do Rio dos Sinos, Brasil

Leonel Aguiar, Pontifícia Universidade Católica do Rio de Janeiro, Brasil

Luciana Panke, Universidade Federal do Paraná, Brasil

Marcelo Kischinhevsky, Universidade do Estado do Rio de Janeiro, Brasil

Raquel Paiva, Universidade Federal do Rio de Janeiro, Brasil

Sandra Rubia da Silva, Universidade Federal de Santa Maria, Brasil

EDIČ̃̃ DE TEXTO E RESUMOS I Susane Barros

SECRETÁRIA EXECUTIVA I Juliana Depiné

EDITORAÇ̃̃o ELETRÔNICA I Roka Estúdio

TRADUÇÃO I Sieni Campos
COMPós I www.compos.org.br

Associação Nacional dos Programas de Pós-Graduação em Comunicação

Presidente

Eduardo Morettin

Universidade de São Paulo, Brasil

eduardomorettin@usp.br

Vice-presidente

Inês Vitorino

Universidade Federal do Ceará, Brasil

ines@ufc.br

Secretária-Geral

Gislene da Silva

Universidade Federal de Santa Catarina, Brasil

gislenedasilva@gmail.com 